\title{
Optical hydrogen sensing properties of nanostructured Pd/MoO3 films.
}

\begin{abstract}
In this work, molybdenum trioxide (MoO3) nanostructured films were deposited onto quartz substrates via thermal evaporation of $\mathrm{MoO} 3$ powder. Subsequently, a catalytic palladium (Pd) layer was deposited onto $\mathrm{MoO} 3$ layer by e-beam evaporation. Scanning electron microscopy (SEM) revealed $\mathrm{MoO} 3$ nanorods grown in various directions and X-ray diffraction (XRD) confirmed the growth of orthorhombic MoO3. Optical hydrogen $(\mathrm{H} 2)$ sensing performance of nanostructured $\mathrm{Pd} / \mathrm{MoO} 3$ films were investigated at a concentration between 0.06-1\%. It was observed that the nanostructured films exhibited excellent gasochromic characteristics and remarkable absorbance changes in near infrared (NIR) wavelength range (750-1000 nm) when exposed to $\mathrm{H} 2$. $\mathrm{Pd} / \mathrm{MoO} 3 \mathrm{~T} 90 \%$ response and recovery towards $0.06 \% \mathrm{H} 2$ were 150 and $300 \mathrm{~s}$, respectively. The film operating temperature was also found as low as $120^{\circ} \mathrm{C}$.
\end{abstract}

Keyword: Pd/MoO3 Nanostructures; Optical hydrogen sensing; Thermal evaporation. 